Haya: The Saudi Journal of Life Sciences

Abbreviated Key Title: Haya Saudi J Life Sci ISSN 2415-623X (Print) |ISSN 2415-6221 (Online) Scholars Middle East Publishers, Dubai, United Arab Emirates Journal homepage: https://saudijournals.com/sjls

Review Article

\title{
Role of Chlorpyrifos in Experimentally based Rats
}

\section{Zeeshan Laghari ${ }^{1}$, Noshaba Manawar ${ }^{2 *}$, Shahla Akash ${ }^{2}$, Ayesha Saddique $^{2}$, Mehwish Malik $^{2}$, Irha Basit ${ }^{3}$, Hamza Rafeeq $^{3}$,} Nabeela Fatima ${ }^{3}$

${ }^{1}$ Department of Zoology, Government College University, Faisalabad, Pakistan

${ }^{2}$ Department of Zoology, Wildlife and Fisheries, University of Agriculture, Faisalabad

${ }^{3}$ Department of Biochemistry, University of Agriculture, Faisalabad

DOI: $10.36348 /$ sjls.2020.v05i10.005 $\quad$ | Received: 27.09.2020 | Accepted: 08.10.2020 | Published: 29.10 .2020

*Corresponding author: Noshaba Munawar

\section{Abstract}

Chlorpyrifos exposure may lead to acute toxicity at higher dose persistent health effects follow acute poisoning or from long term exposure to low dose, and developmental effects appear in fetuses and children even at very small dose. The aims and objective of this review article is to study the toxicity and biochemical effects of chlorpyrifos on different body organs of Male Sprague Dawely Rats. The danger of using chlorpyrifos persists either it is used in high amount or in low amount so it must be used when it is needed most. The administration of chlorpyrifos to rats induced testicular and cardiac toxicities significant decrease in serum testosterone, FSH and LH levels as well as the significant increase in CK-MB, LDH and AST activities. In liver and kidney tissues, dimension of glutathione and the action of superoxide dismutase and catalase chemicals altogether diminished by chlorpyrifos. Chlorpyrifos and lead acetate prompted change in serum and lipid outlines and observe oxidative pressure. Biochemical investigation demonstrated that organizations of the chlorpyrifos and deltamethrin obviously cause liver harm. Also sertoli cells and decrease in number of sperm count as the main factor for chlorpyrifos. These changes more obvious in rats: treated with higher dose of chlorpyrifos. So it is concluded that chlorpyrifos leads to such changes in living organisms included the rats as well as in humans.

Keywords: Chlorpyrifos, Biochemical effects, Toxicity, Liver, lipid peroxidation.

Copyright () 2020 The Author(s): This is an open-access article distributed under the terms of the Creative Commons Attribution 4.0 International License (CC BY-NC 4.0) which permits unrestricted use, distribution, and reproduction in any medium for non-commercial use provided the original author and source are credited.

\section{INTRODUCTION}

Children are more likely to experience muscle weakness rather than twitching; excessive saliva rather than sweat or tears; seizures; and sleepiness or coma. Monitoring studies show that almost $82 \%$ of population had measurable levels of urinary 3, 5, 6-trichloro-2pyridinol (TCP), a primary metabolite of chlorpyrifos, indicating recent exposure. Acute poisoning is probably most common in agricultural areas in Asia, where many small farmers are affected [1].

Chlorpyrifos exposure may lead to acute toxicity at higher dose persistent health effects follow acute poisoning or from long term exposure to low dose, and developmental effects appear in fetuses and children even at very small dose. The disturbance in the serum and tissue lipid profiles due to CPF can cause atherosclerosis and coronary heart disease. Exposure to $\mathrm{CPF}$, acutely or chronically, caused a dose-dependent increase in DNA damage in the liver and brain of rats. From the present study, it can be concluded that CPF exhibits genotoxic potential in vivo. Organophosphates are thought to constitute two thirds of ingested pesticides in rural Asia [2].

The pesticides reach soil one way or other. Many are applied directly on the surface or injected into the upper layers of the soil. However, from the aspect of environmental pollution, extensive use of pesticides and other agrochemicals not only limits plants growth but may also induce mutagenic and carcinogenic effects on none target microorganisms. Although pesticides may not be universally toxic to all species of microorganisms, they have the potential disturbing microbial events/activities in the environment, polluted by these chemicals. There are many pesticides and insecticides to which pests and insects are resistant [3]

As a result they are not degraded; like chlorpyrifos in the environment by routine processes. These undegradable compounds however are degradable by bacterial activity. But if pesticides are not degraded then persistence of pesticides in food chain and the development of resistance in pests 
towards pesticides are the two serious problems present [4].

The aims and objective of this review article is to study the toxicity and biochemical effects of chlorpyrifos on different body organs of Male Sprague Dawely Rats. The danger of using chlorpyrifos persists either it is used in high amount or in low amount so it must be used when it is needed most.

\section{Biochemical Effects chlorpyrifos}

The administration of chlorpyrifos and methomyl to rats induced testicular and cardiac toxicities that were evidenced by the histological deteriorated changes and the significant decrease in serum testosterone, FSH and LH levels as well as the significant increase in CK-MB, LDH and AST activities. Chlorpyrifos and methomyl-administered rats exhibited a significant increase in testes and heart lipid peroxidation as well as a significant decrease in reduced glutathione content and superoxide dismutase, glutathione peroxidase and glutathione-S-transferase activities. Concomitant as well as the nutritional supplementation with Salvia officinalis or Ruta graveolens markedly prevented chlorpyrifos- and methomyl-induced biochemical and histopathological alterations. These findings provide evidence that Salvia officinalis and Ruta graveolens ethanolic extracts could prevent chlorpyrifos and methomylinduced testicular and cardiac toxicities in rats through potentiation of the antioxidant defense system $[5,6]$.

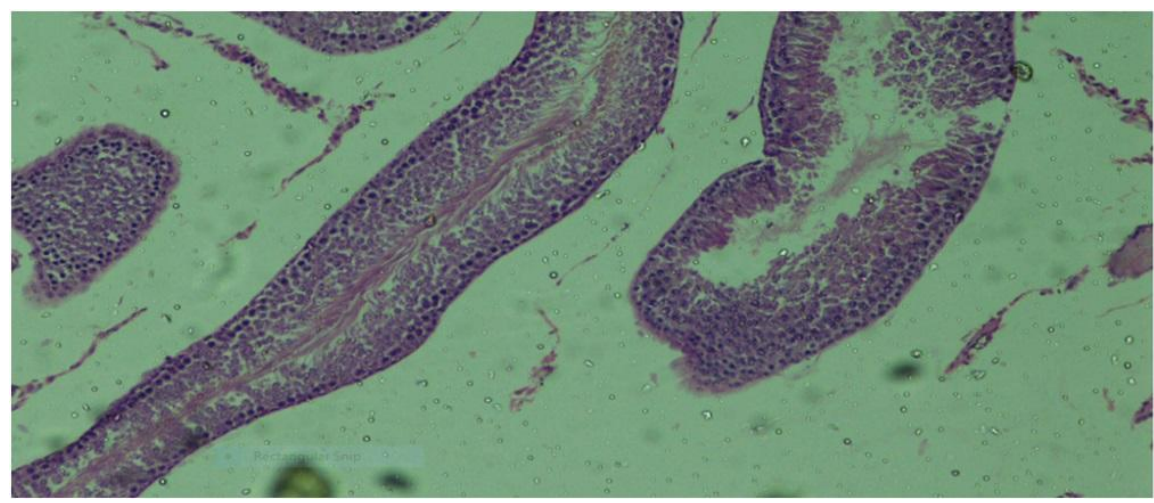

Fig-1: Decrease in sperm cells due to biochemical effects of Chlorpyrifos

Thirty-two strong male rodents that isolated into two social occasions in the previous studies: a CPF-revealed assembling and a control-trap gathering. Control-fabrication group got corn oil $(0.20 \mathrm{~mL}$ consistently). The CPF was coordinated orally to male rodents at $37 \mathrm{mg} \mathrm{kg}-1 \mathrm{BW}$ for 45 days to evaluate the conceptive threat. In all rodents, testing for histological and sperm examinations was performed on days 5,15 , 30 and 45 . The CPF caused a basic $(p<0.05)$ decrease in sperm count, common sense and motility and extended energetic sperms and DNA hurt in sperm cells. Light infinitesimal examinations revealed extended caught spermatogenesis, negative adjusted division and repopulation records and lessened Leydig cells number. These disclosures demonstrate that CPF effectsly influences sperm cells and conceptive plan of male rodents [7].

Twenty five pale cleaned individual wistar rodents pondering between $150-200 \mathrm{~g}$ alienated into five social affairs covering five rodents each. $\mathrm{CPF}$ at 0 (control), 18.9, 25.9, 32.2 and 39. $2 \mathrm{mg} / \mathrm{kg}$ were given from mouth to masculine rodents, independently for about a month, in the significant lots of May and June. Result revealed basic lessening in the body loads. The stuffed cell volume (PCV), hemoglobin ( $\mathrm{Hb}$ ) and lymphocytes moreover shown immense diminishing at $39.2,25.9$ and $32.2 \mathrm{mg} / \mathrm{kg}(39.33,45.40$ and $44.80 \%)$, independently appeared differently in relation to control
(49.69\%). There is colossal tallness of serum transaminase aspartate transaminase and alanine transaminase and fundamental alkaline phosphatase from 32.2, 39.2 and $25.9 \mathrm{mg} / \mathrm{kg}$ dosages, correspondingly. Moreover test pickled social events showed set apart of full scale protein and adjusted egg whites and globulin substance stood out from control. There was partition subordinate addition of histopathological changes [8].

Two social occasions of wistar pale cleaned individual rodents were partition orally for around two months with CPF in vegetable oil $(0.1 \mathrm{mg} / \mathrm{kg} \mathrm{Bw}$ and $2.5 \mathrm{mg} / \mathrm{kg} \mathrm{Bw}$ and control pack was given simply vegetable oil) a basic $\mathrm{P}<0.05$ increase in complete plasma proteins in rodents treated with higher bit $2.5 \mathrm{mg} / \mathrm{kg} \quad \mathrm{Bw}$ was watched a known significant $(\mathrm{P}<0.01)$ decrease in the liver glycogen regard in higher segment was viewed. $2.5 \mathrm{mg} / \mathrm{kg}$ bw assembling, no gigantic change in the blood urea regard was found in the respected rodents when appeared differently in relation to control. A colossal $(\mathrm{P}<0.01)$ increase in the liver alanine aminotransferase and lactate dehydrogenase compound development was seen in both treated social occasions. Degenerative histological changes like leucocyte intrusion. Augmentation in Kupffer cells. Amplified blood sinusoids and cytoplasmic vacuolization in liver and kidney were seen in treated rodents. The result shows that sub- 
interminable introduction of CPF impacts liver and kidney unfairly [9].

\section{Effects of Chlorpyrifos on body Organs}

In liver and kidney tissues, dimension of glutathione and the action of superoxide dismutase and catalase chemicals altogether diminished, while the dimension of lipid peroxidation fundamentally expanded contrasted with the control gathering. The lower dosages of (ADI, NOAEL) PM instigated immaterial or restricted modification in the previously said biochemical parameters. Histopathological examination uncovered hepato-renal cell harm in every tried portion of PM contrasted with untreated gathering. The power of the abuse in hepatic and renal works just as oxidative harm spoken to by biochemical adjustments and histopathological discoveries were exhibited in a portion subordinate way [10].

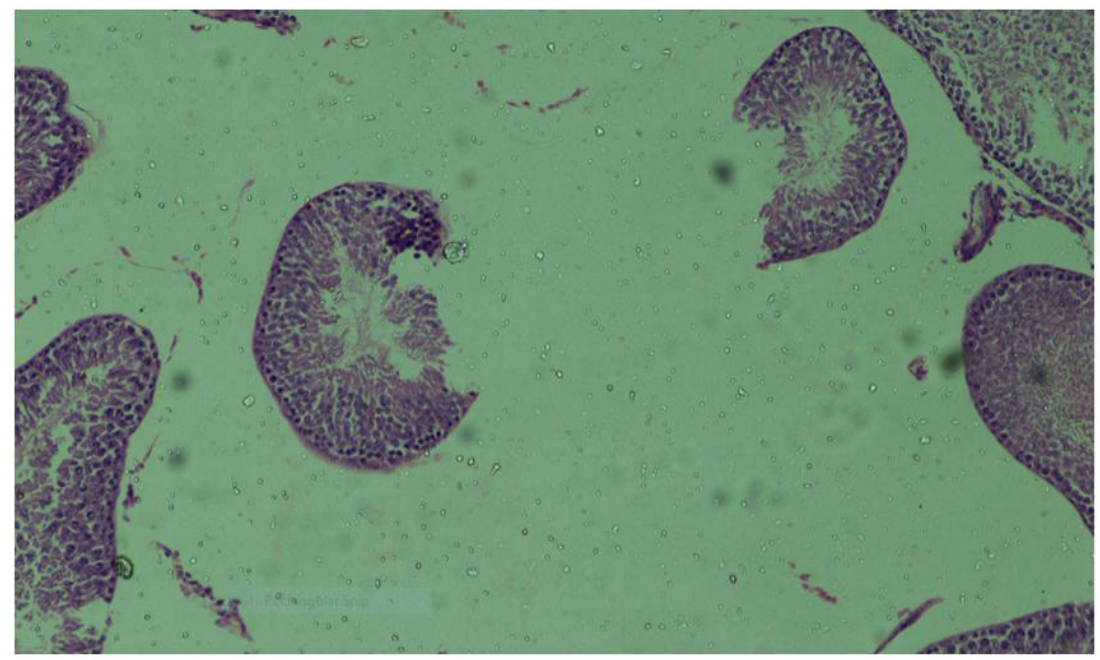

Fig-2: Effects of Chlorpyrifos on testicular cells of rats

Chlorpyrifos and lead acetate prompted change in serum and lipid outlines and observe oxidative pressure. Taurine reduced the interruptions in the serum and also lipid outlines of the rodents somewhat by moderating oxidative pressure. No decision encouraging test was directed on grown-up male and female pale skinned person rodents benefited from harmed diet containing chlorpyrifos (at 200ppm), or chlorpyrifos-methyl (at 2000ppm) for 12 weeks pursued by 3 weeks of recuperation period. At 2, 4, 6, 8, 10, 12 weeks post treatment and following 3 weeks of recuperation periods, number of male and female rodents were yielded, blood tests were gathered and their organs were analyzed out and gauged. All out protein, all out lipid and glucose substance were resolved in plasma, liver and mind of treated and control rodents. Results demonstrated that no lethal side effects were seen amid the experimentation time frame, however the body weight additions of treated rodents were not as much as that of control[11].

In treated rodents, the overall loads of heart, lungs, liver, spleen, kidneys and cerebrum of both genders just as ovaries indicated noteworthy increments, while male testicles and sperm tallies demonstrated critical declines contrasted with those of control rodents. For both treated genders, there were noteworthy increments in absolute lipid content while the all out protein and glucose substance were fundamentally diminished contrasted with those of control rodents. By and large, there were no critical contrasts between the two rodent genders in connection to the above antagonistic impacts. Be that as it may, these impacts were more articulated with chlorpyrifos than with chlorpyrifos-methyl and these impacts expanded with expanding the nourishing time frame on harmed diet. Amid the recuperation time frame, all these antagonistic impacts were bit by bit improved [12].

The parameters such as acetylcholinesterase, dimensions of malondialdehyde as a marker of lipid peroxidation; diminished glutathione, catalase and superoxide dismutase assessed in cerebrum tissue. Organization of CPF for 28 days prompted a noteworthy increment in LPO levels and hindrance in cerebrum AChE movement. Likewise, results indicated noteworthy reductions in GSH substance, CAT and SOD exercises in mind. Supplementation with grape seed proanthocyanidin concentrate to treated creatures fundamentally $(\mathrm{P}<0.05)$ lessened the harmfulness and oxidative pressure evoked by CPF [13-5].

There was the decreasing in mass of rats displayed to bug splashes with CPF being the most pretentious. Rats displayed to ACM (alphacypermethrin) and the control presented no physiological variations while those exhibited to CPF and dichlorvos demonstrated membrane wounds and excited bladder independently. Histology of nerves of cerebrum, liver, lung and kidney exhibited swelling, aggravations, blockages, nephritis and spoil. Hematological limits demonstrated important reduction in RBC'S (Red Blood Cell), Hemoglobin and PCV 
$(\mathrm{P}<0.05)$ beside the WBC'S, which extended inconsequentially $(\mathrm{P}>0.05)$. Biochemical limitations showed irrelevant augmentation in AAT (Aspartate aminotransferase), ALP (Alkaline phosphatase), creatinine and urea levels $(\mathrm{P}>0.05)$ excluding for the AP (Alanine phosphatase) which exhibited a vital addition $(\mathrm{P}<0.05)$. Semen examination exposed reduced sperm activity and irregular sperm cells $[16,17]$.

Huge decrease in body weight and height in renal weight seen in bug sprays presented rodents contrasted with control. Huge bothers of renal capacity as confirm through increment in blood urea nitrogen and serum creatinine level were seen in treated rodents. Additionally, renal oxidative harm seen in bug spray regarded rodents as confirm by means of growth in kidney lipid peroxidation just as exhaustion in kidney cancer prevention agent chemicals; catalase, superoxide dismutase and glutathione peroxidase. Histopathological investigation of the kidney uncovered that supplementation with brought about nil to mellow in vacuolization, swelling and degeneration in the endothelium of glomerular tuft. All in all, the utilization of green tea remove gave off an impression of being valuable to rodents, as it were, by constricting and reestablishing the harm continued by bug spray presentation [18].

At low dosages, decrease in the plasma dimensions of testosterone and $\mathrm{FSH}$ and $\mathrm{LH}$ hormones alongside the huge shrinkage of seminiferous tubules and gametogenic changes in germ cells were taken note. In any case, these progressions were reestablished with the recovery of serum testosterone, FSH and LH alongside relapse of testis at higher portions [19-22]. Also, dimension of testicular lipid peroxidation was raised, though dimensions of cancer prevention agent chemicals superoxide dismutase, catalase and steroidogenic catalysts exercises $(\Delta 5, \quad 3 \beta$ hydroxysteroid dehydrogenase and was decreased fundamentally at low dosages [23-25]. Be that as it may, rodent testicles demonstrated a noteworthy decline in lipid peroxidation and associative increment in cell reinforcement proteins and steroidogenic compounds exercises at higher portions. Higher portions of chlorpyrifos medicines, rodent testicles were appeared trigger their common guard component which ended up usable perhaps through remedial proportion of union of cell reinforcement protection compounds and steroidogenic catalysts and pituitary gonadotrophins hormone input instruments [26-29].

There was a connection between CPF organization and the noteworthy abatement of the sperm checks, spermatozoon survival and testosterone level just as increment of sperm deviations [30]. CPF expanded fundamentally the lipid profile and the dimensions of different serum liver marker compounds. Conversely, co-organization of propolis to CPF-treated rodents reestablished practically the vast majority of these biochemical parameters to ordinary dimensions. Then again, CPF brought about histopathological changes in testicles of male rodents [25]. Be that as it may, pre-organization of propolis to CPF-treated creatures improved the testicular harm and mitigates the lethal impacts of $\mathrm{CPF}$ on regenerative capacities in male rodents [31].

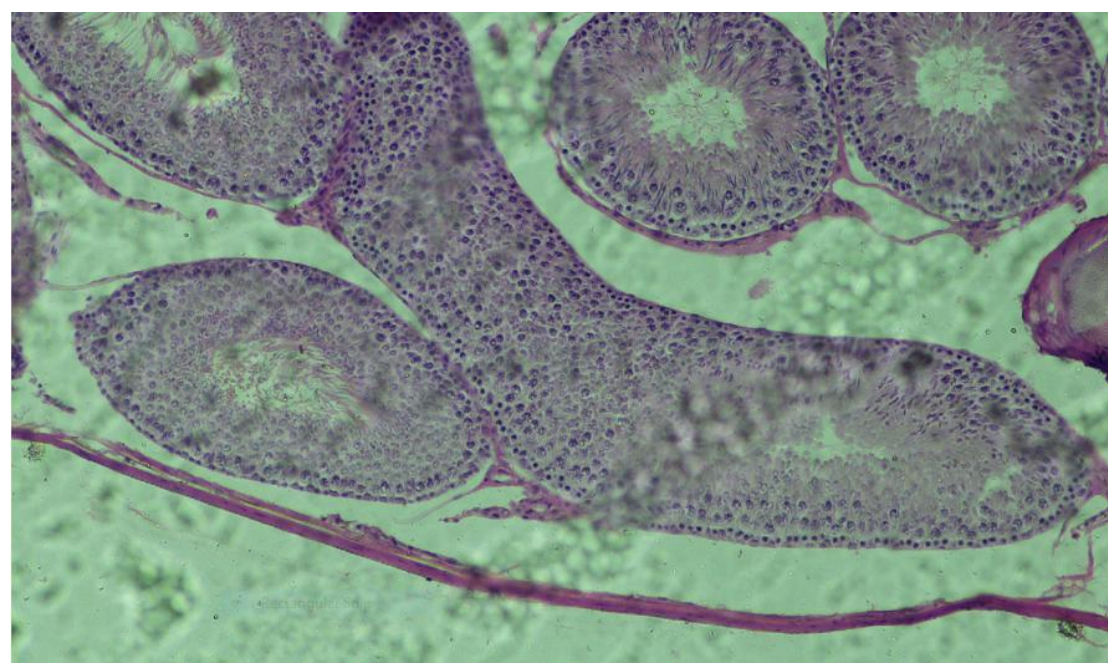

Fig-3: Shows the spermatozoa due to chlorpyrifos

Antioxidative guard instruments and lipid peroxidation in rodent liver tissues show distinctive reactions relying upon various pesticide medications and portions [22]. Biochemical investigation demonstrated that organizations of the chlorpyrifos and deltamethrin obviously cause liver harm. Lipid peroxidation levels are higher at high portions than at low dosages, yet DM caused more articulated increment than CP. Tentatively, oxidant-cell reinforcement balance is more influenced by deltamethrin treatment [23].

\section{CONCLUSION}


The previous literature data has shown the significant increase in ALP, ALT, AST leads the serious damage in the body organs that results in breakage of these enzymes into blood stream. It might result due to significant damage can also be seen in the cells of testis due to degeneration, hemorrhage, in seminiferous tubules and germ line wall. Also sertoli cells and decrease in number of sperm count as the main factor for chlorpyrifos. These changes more obvious in rats: treated with higher dose of chlorpyrifos. So it is concluded that chlorpyrifos leads to such changes in living organisms included the rats as well as in humans.

\section{REFERENCES}

1. Aguilera-Méndez, A., Fernández-Lainez, C., Ibarra-González, I., \& Fernandez-Mejia, C. (2012). The chemistry and biochemistry of niacin (B3). In $B$ Vitamins and Folate (pp. 108-126).

2. Ahmad, I., Khan, S., Naeem, M., Hayat, M., Azmi, U. R., Ahmed, S., \& Irfan, M. (2019). Molecular Identification of Ten Palm Species using DNA Fingerprinting. Int. J. Pure App. Biosci, 7(1), 46-51. 14.

3. Abushita, A. A., Hebshi, E. A., Daood, H. G., \& Biacs, P. A. (1997). Determination of antioxidant vitamins in tomatoes. Food Chemistry, 60(2), 207212.

4. Brown, B. G., Zhao, X. Q., Chait, A., Fisher, L. D., Cheung, M. C., Morse, J. S., ... \& Frohlich, J. (2001). Simvastatin and niacin, antioxidant vitamins, or the combination for the prevention of coronary disease. New England Journal of Medicine, 345(22), 1583-1592.

5. Doherty, J. U., Gluckman, T. J., Hucker, W. J., Januzzi, J. L., Ortel, T. L., Saxonhouse, S. J., \& Spinler, S. A. (2017). 2017 ACC expert consensus decision pathway for periprocedural management of anticoagulation in patients with nonvalvular atrial fibrillation: a report of the American College of Cardiology Clinical Expert Consensus Document Task Force. Journal of the American College of Cardiology, 69(7), 871-898.

6. Fairfield, K. M., \& Fletcher, R. H. (2002). Vitamins for chronic disease prevention in adults: scientific review. Jama, 287(23), 3116-3126.

7. Gast, G. C. M., de Roos, N. M., Sluijs, I., Bots, M. L., Beulens, J. W., Geleijnse, J. M., ... \& van der Schouw, Y. T. (2009). A high menaquinone intake reduces the incidence of coronary heart disease. Nutrition, Metabolism and Cardiovascular Diseases, 19(7), 504-510.

8. Gast, G. C. M., de Roos, N. M., Sluijs, I., Bots, M. L., Beulens, J. W., Geleijnse, J. M., ... \& van der Schouw, Y. T. (2009). A high menaquinone intake reduces the incidence of coronary heart disease. Nutrition, Metabolism and Cardiovascular Diseases, 19(7), 504-510.

9. Ghani, U., Bukhari, S. S. H., Ullah, S., Rafeeq, H., Saeed, M. M., Amjad, A., \&amp; Taufiq, T.
(2019). A review on Nutraceuticals as a Therapeutic Agents. International Journal of Biosciences, 15(5), 326-340.

10. Ghani, U., Naeem, M. Bukhari, S.S.H., Yar, G., Tariq, I., Siddique, S., Nawaz, H.A., Pal, Z.A.A., Nasim, F. and Bukhari, S.A.H. (2019). Prevalence and Risk Factors associated with Hepatitis B and Hepatitis $\mathrm{C}$ and their Correlation with Inflammatory Markers among Southern Region of Punjab. Biological Forum - An International Journal, 11(2): 136-143.

11. Hussain, A., Rafeeq, H., Asghar, A., Ullah, S., Imtiaz, U., Ullah, H., \&amp; Ilyas, M. D. Combined inhibitory potential of Ammonium thiosulphate and 2-chloro-6-(trichloromethyl) pyridine on ureases activities.

12. Naeem, M., Hayat, M., Azmi, U. R., Ahmed, S., \&amp; Irfan, M. (2019). Molecular Identification of Ten Palm Species using DNA Fingerprinting. Int. J. Pure App. Biosci, 7(1), 46- 51.

13. Naeem, M., Hayat, M., Qamar, S. A., Mehmood, T., Munir, A., Ahmad, G., \& Hussain, A. (2019). Risk factors, genetic mutations and prevention of breast cancer. Int. J. Biosci, 14(4), 492-496.

14. Usman, G., Muhammad, N., Hamza, R., Usman, I., Ayesha, A., Saqib, U., \& Fatima, Q. (2019). A Novel Approach towards Nutraceuticals and Biomedical Applications. Scholars International Journal of Biochemistry, 2(10), 245-252.

15. Naeem, M., Ashraf, A., Safdar, H. M. Z., Khan, M. Q., Rehman, S. U., Iqbal, R., ... \& Ahmad, G. Biochemical changes in patients with chronic kidney failure in relation to complete blood count and anemia.

16. Muhammad Naeem, Muhammad Mujahid, Asim Umer, Siraj Ahmad, Ghafoor Ahmad, Jabir Ali, Sayed Jasim Raza Zaidi, Muhammad Zohaib Hassan, Tania Zaheer, Irfan Khalid. New trends in removing toxic metals from drinking and wastewater by biomass materials and advanced membrane technologies. J. Bio. Env. Sci. 15(3), 1017, September 2019.

17. Naeem, M., Ali, J., Hassan, M. Z., Arshad, B., Rao, M. H. I., Sarmad, M. S. K., \& Hassan, M. U. (2019). Novel Approach towards DNA Barcoding as a Tool in Molecular Biologyand Biological Activities of Cyclotides with Particular Emphasizes at Molecular Level. In Biological Forum-An InternationalJournal (Vol. 11, No. 2, pp. 83-96).

18. Rafeeq, H., Arshad, M. A., Amjad, S. F., Ullah, M. H., Muhammad, H., Imran, R. K., ... \&amp; Ajmal, H. Effect of Nickel on Different Physiological Parameters of Raphanus Sativus.

19. Rafeeq, H., Tanvir, K., Khan, M. A. B., Basit, I., Ul, Q., Ain, F. F., ... \& amp; Siddique, S. An Effective Approach towards Heavy Metals and their Effects on Different Organs of the Body.

20. Saim, S., Watson, S. (2006). Heart Outcomes Prevention Evaluation (HOPE) 2 Investigators. Homocysteine lowering with folic acid and B 
vitamins in vascular disease. New England Journal of Medicine, 354(15), 1567-1577.

21. Sies, H., Stahl, W., \& Sundquist, A. R. (1992). Antioxidant functions of vitamins: Vitamins $\mathrm{E}$ and $\mathrm{C}$, Beta- Carotene, and other carotenoids a. Annals of the New York Academy of Sciences, 669(1), 720.

22. Shafiq, S., Adeel, M., Raza, H., Iqbal, R., Ahmad, Z., Naeem, M., \& Azmaai, U. R. (2019). Effects of Foliar Application of Selenium in Maize (Zea Mays L.) under Cadmium Toxicity. In Biological Forum-An International Journal, 11(2): 27-37.

23. Mucida, D., Park, Y., Kim, G., Turovskaya, O., Scott, I., Kronenberg, M., \& Cheroutre, H. (2007). Reciprocal TH17 and regulatory $\mathrm{T}$ cell differentiation mediated by retinoic acid. Science, 317(5835), 256-260.

24. Uzun, F. G., Kalender, S., Durak, D., Demir, F., \& Kalender, Y. (2009). Malathion-induced testicular toxicity in male rats and the protective effect of vitamins $\mathrm{C}$ and $\mathrm{E}$. Food and chemical toxicology, 47(8), 1903-1908.

25. Zeeshan, L., Nimra, M., Maryam, H., Bahzad, A.F., Huda, Z., Sidra, H., Irha, B., Muhammad, I., Ansa, Y., Muhammad, H.A., Usman, G. (2020). Effects of chlorpyrifos on testicular biochemistry and physiology of male sprague dawely rats. Int. J. Biosci. 17(1), 75-87, July 2020.
26. Asim, H., Naima, N., Ayesha, L., Misbah, W., Maryam, A., Nida, A. (2020). A Comprehensive Review on Diabetic Retinopathy and Mental Disorders. IOSR Journal of Biotechnology and Biochemistry, 6(3): 38-51.

27. Maqsood, S., Qadir, S., Hussain, A., Asghar, A., Saleem, R., Zaheer, S., \& Nayyar, N. Antifungal Properties of Copper Nanoparticles against Aspergillus niger.

28. Ullah, S., Hussain, A., Asghar, A., Ali, H., Ullah, K., Ilyas, M. D., ... \& Kiran, I. Establishment of Mouse Model for Obesity and Type 2 Diabetes and Expression of Secreted Frizzled Related Protein 4 (SFRP-4) As A Biomarker. Proteins ( $g \%), 31,23$.

29. Ansari, N., Hussain, A., Kiran, I., Ajaz, M. H., Azam, T., \& Ghafoor, A. Applications of Biotechnological Techniques in Healthcare, Current Advancements and Future Directions.

30. Ali, J., Hussain, A., Maqsood, S., Imtiaz, U., Laeeq, R., Zulfiqar, M., \& Hussain, I. Genetic Basis and Risk Factors Associated with Breast Cancer.

31. Maryam, P., Syed, N.S., Asim, H., Salman, M., Usman, I., Haris, A., Saifur, R., Sayyad, H. M., Sidra, R., Arzoo, R., Sadia, Z. (2019). Applications of DNA barcoding and future directions. Journal of Biodiversity and Environmental Sciences. 